\title{
OBSERVAÇÕES SOBRE OS HÁBITOS DE Rhynchonycteris naso (WIED-NEUWIED, 1820) E Noctilio albiventris DESMAREST, 1818 (MAMMALLIA, CHIROPTERA)
}

\author{
MARCELO RODRIGUES NOGUEIRA e ANDRÉ POL \\ Instituto de Biologia, Universidade Federal Rural do Rio de Janeiro, CEP 23851-970, Seropédica, RJ \\ Correspondência para: Marcelo Rodrigues Nogueira, Instituto de Biologia, Universidade Federal \\ Rural do Rio de Janeiro, CEP 23851-970, Seropédica, RJ \\ Recebido em 21/05/97 - Aceito em 27/05/98 - Distribuído em 28/08/98
}

(Com 2 figuras)

\section{ABSTRACT \\ Observations about Rhynchonycteris naso (WIED-NEUWIED, 1820) and Noctilio albiventris DESMAREST, 1818 (MAMMALIA, CHIROPTERA)}

Observations about Rhynchonycteris naso and Noctilio albiventris were carried out in the Jaíba region, northern Minas Gerais State, Brazil. Colonies of these bats were found in association with watercourses in areas under considerable antropic influence. The night activity of both species began about half an hour after sunset during approximately one hour. A second period of activity was noted in $R$. naso, and in the majority of $N$. albiventris. These bats used temporary night roosts, observing formation of clusters in the later. Capture, with mist-nets, of lactating females in April and October suggest that in this area both species present a bimodal poliestric reproductive pattern, with peaks of births at the beginning and the end of wet season (October to March). The occurrence in sympatry of these species must be facilitated by the greater opportunism of $N$. albiventris in relation to the foraging areas and due to its capacity of exploring aquatic insects.

Key words: Chiroptera, Rhynchonycteris naso, Noctilio albiventris, activity pattern, reproduction.

\section{RESUMO}

Observações sobre os hábitos de Rhynchonycteris naso e Noctilio albiventris foram conduzidas na região de Jaíba, ao norte do Estado de Minas Gerais. Colônias dessas espécies foram amostradas em associação com cursos d'água em áreas sob considerável ação antrópica. Houve sobreposição em relação ao período de atividade que se inicia cerca de meia hora após o pôr-do-sol e dura em torno de uma hora. Um segundo período de atividade ao final da noite, e com mesma duração, foi constatado em $R$. naso e na maioria dos indivíduos de N. albiventris. Ambas as espécies utilizam abrigos noturnos temporários, observando-se em $N$. albiventris a formação de agrupamentos. Capturas em mist-nets de fêmeas lactantes nos meses de abril e outubro sugerem que nessa região ambas as espécies apresentam um padrão reprodutivo poliestro bimodal, com picos de nascimento no início e ao final do período chuvoso (outubro a março). A ocorrência em simpatria dessas espécies deve ser facilitada pelo maior oportunismo de $N$. albiventris em relação as áreas de forrageio e por sua capacidade de explorar insetos aquáticos.

Palavras-chave: Chiroptera, Rhynchonycteris naso, Noctilio albiventris, padrão de atividade, reprodução.

\section{INTRODUÇÃO}

Rhynchonycteris naso (Emballonuridae) e Noctilio albiventris (Noctilionidae) são duas espé- cies de morcegos exclusivamente neotropicais e simpátricas na maior parte de suas distribuições geográficas, ocorrendo a primeira desde o sul do México até o norte do Peru e Brasil central, in- 
cluindo ainda Trinidad, e a segunda do sul do México até o norte da Argentina (Nowak, 1994).

$R$. naso pesa em média 4,5 g, é insetívoro e abriga-se sobre troncos de árvores, rochas e construções humanas, preferencialmente adjacentes ou sobre cursos d'água (Bradbury \& Vehrencamp, 1976). N. albiventris pesa cerca de $30 \mathrm{~g} \mathrm{e}$, apesar de algumas evidências associando-o a hábitos frugívoros e piscívoros (Howell \& Burch, 1974), é primariamente insetívoro, utilizando ocos de árvores e construções humanas como abrigos diurnos (Hood \& Pitocchelli, 1983).

Ambas as espécies são freqüentemente observadas sobre coleções d'água onde concentram suas atividades de forrageio (Goodwin \& Greenhall, 1961; Tuttle, 1970; Bradbury \& Vehrencamp, 1976; Reis, 1984), sendo o maior porte de $N$. albiventris um fator que, de acordo com o postulado por McNab (1971), permitiria sua coexistência com $R$. naso sem que houvesse sobreposição de nichos, já que $N$. albiventris utilizaria presas presumivelmente maiores. Outros fatores que também poderiam influenciar na partilha de alimento são a estratificação vertical e o padrão de atividade das espécies (McNab, 1971). Estudando populações simpátricas de $N$. albiventris e Noctilio leporinus, Hooper \& Brown (1968) sugeriram ainda que, além dos fatores citados, um período reprodutivo distinto também contribuiria para redução da competição interespecífica.

Como ressaltado por McNab (1971), o conhecimento sobre a história natural das diferentes espécies é essencial para uma melhor compreensão da complexa estrutura observada nas comunidades de morcegos tropicais. Durante trabalhos de campo realizados na região de Jaíba, norte de Minas Gerais, obteve-se uma série de informações sobre os hábitos de $R$. naso e $N$. albiventris, incluindo seus padrões de atividade, estratégia reprodutiva e relações intra e interespecíficas, as quais são apresentadas, contribuindo para um maior entendimento da biologia e ecologia dessas espécies.

\section{MATERIAL E MÉTODOS}

Os hábitos de R. naso e $N$. albiventris foram estudados com base em colônias dessas espécies encontradas nos arredores de Mocambinho (aprox. $15^{\circ} 05^{\prime} \mathrm{S}, 44^{\circ} 00^{\prime} \mathrm{W}$ ), margem direita do médio rio São Francisco, durante trabalhos de campo desenvolvidos entre abril de 1994 e julho de 1995, nas áreas sob influência do Projeto de Irrigação do Jaíba (CODEVASF), municípios de Jaíba e Matias Cardoso, ao norte do Estado de Minas Gerais.

Esta região foi incluída por Andrade-Lima (1981) na porção sul do domínio das caatingas, representando um tipo de formação arbórea por ele denominada caatinga alta, que segundo Fernandes \& Bezerra (1990) é extremamente rara em relação a outras formações desse bioma. A proximidade do domínio dos cerrados (Eiten, 1972) torna complexa a composição florística dessa área, como ressaltado por Veloso et al. (1991), que, em sua classificação da vegetação brasileira adaptada a um sistema universal, a enquadram como floresta estacional decidual submontana. Uma caracterização mais aprofundada da vegetação nas áreas do Projeto Jaíba pode ser encontrada em Magalhães \& Ferreira (1976).

Segundo dados obtidos na Estação Agroclimática de Mocambinho, o clima da região é o Tropical de Savana (AW), com precipitação média anual de 912,02 mm e 5 a 6 meses consecutivos de seca (maio a outubro). A temperatura média anual é de $25,7^{\circ} \mathrm{C}$, com extremos sendo registrados em julho $\left(7,8^{\circ} \mathrm{C}\right)$ e outubro $\left(41^{\circ} \mathrm{C}\right)$.

A maior parte das observações foi realizada em colônias de $R$. naso e $N$. albiventris que coabitavam sob ponte de madeira no riacho Mocambinho, a cerca de $100 \mathrm{~m}$ de sua desembocadura no rio São Francisco. A remanescente mata ciliar deste riacho, que pode ser incluída na formação perenifólia descrita por Magalhães \& Ferreira (1976), encontra-se cercada pelos campos de várzea e antrópicos, também caracterizados por esses autores. Outras colônias de $R$. naso localizavamse sob pontes de madeira em córrego ligado à lagoa do Juazeiro e sob ponte de concreto em canal de irrigação. Durante quatro noites (duas inteiras e duas parciais), em outubro de 1994, através de observação direta nas colônias que coabitavam no riacho Mocambinho, foi obtida a maioria das informações sobre o padrão de atividade e relações intra e interespecíficas de $R$. naso e $N$. albiventris. Observações esporádicas e coletas com mist-nets complementaram as análises. A estratégia reprodutiva dessas espécies foi avaliada com base na presença de fêmeas grávidas, determinadas por apalpação, e lactantes. Exemplares de ambas as espécies, preservados em meio líquido, foram incorporados à coleção A. L. Peracchi, 
atualmente depositada no Instituto de Biologia da Universidade Federal Rural do Rio de Janeiro.

\section{RESULTADOS}

\section{Localização e tamanho das colônias}

Colônias de $R$. naso (5) e $N$. albiventris (2) foram encontradas em abrigos sobre coleções d'água em áreas sob considerável ação antrópica. Ambas as espécies utilizavam pontes de madeira como refúgio diurno, tendo-se observado ainda uma colônia de $R$. naso abrigada sob ponte de concreto em canal de irrigação. Refúgios naturais foram explorados de forma secundária, após distúrbio, por colônias de $R$. naso que ocupavam uma ponte sobre o riacho Mocambinho. Quando perturbados, os animais partiam em grupo, voando próximos à água até um tronco de árvore situado na margem do riacho a cerca de $50 \mathrm{~m}$ da ponte. Outro tronco localizado à mesma distância e que pendia sobre o riacho na margem oposta também era utilizado.

O tamanho das colônias variou entre $3 \mathrm{e}$ aproximadamente 80 indivíduos em $R$. naso e manteve-se constante em $N$. albiventris (8 morcegos). Na ponte sobre o riacho Mocambinho, foram encontradas duas colônias de $R$. naso com cerca de 80 e 10 indivíduos. Cada uma ocupava um lado da ponte e os morcegos permaneciam pousados sob as vigas de madeira. Esse mesmo local era coabitado pelas duas colônias de $N$. albiventris que se abrigavam nas frestas entre as vigas (ver Fig. 1). Uma colônia de R. naso com cerca de 30 indivíduos foi observada durante a estação chuvosa em ponte de madeira sobre córrego ligado à lagoa do Joazeiro, mas abandonou o local na época de estiagem quando a água sob o abrigo havia secado. As demais colônias permaneceram em seus abrigos durante todo o período de estudo (16 meses).

\section{2. Áreas de forrageio}

$N$. albiventris foi vista mais freqüentemente voando sobre cursos d'água, tendo sido também observada nas proximidades destes em áreas de várzea e curiosamente sobre uma rodovia asfaltada, onde um exemplar foi atropelado. $R$. naso, entretanto, foi registrada apenas sobre cursos d'água, incluindo canais de irrigação. Ambas as espécies parecem restringir seus vôos a até $1,5 \mathrm{~m}$ acima da superfície da água e, no caso de $N$. albiventris, também do solo. A conspícua coloração alaranjada desta última espécie, que é facilmente distinguida de $N$. leporinus por seu menor porte, permite uma melhor visualização de suas atividades de forrageio, tendo-se notado, durante observações realizadas no rio São Francisco, que diversos morcegos tocavam a superfície da água com certa regularidade.

\section{Padrão de atividade}

Colônias de $R$. naso partiam para o forrageio cerca de 25 minutos após o pôr-do-sol, retornando em média 1 hora e vinte minutos mais tarde. Tal regresso, entretanto, restringia-se a uma parcela estimada em torno de $30 \%$ a $40 \%$ do total de integrantes da colônia, notando-se entre estes a presença de fêmeas que haviam deixado seus filhotes no abrigo. Por volta das 4 horas, os exemplares de $R$. naso presentes na ponte saíam para um segundo forrageio e, entre 5 horas e $5 \mathrm{~h} 10$, cerca de 20 minutos antes do nascer do sol, retornavam juntamente com os demais componentes das colônias.

$N$. albiventris iniciava o forrageio também por volta de 25 minutos após o pôr-do-sol e, cerca de 40 minutos mais tarde, um número de morcegos bem superior ao que havia saído começava intensa movimentação de chegada, o que durava em torno de 1 hora. Aproximadamente 200 indivíduos pousavam, um a um, ocupando frestas em um local não utilizado pelas duas colônias que se abrigavam na ponte durante o dia. Entre $3 \mathrm{~h} 50 \mathrm{e}$ $4 \mathrm{~h} 20$, os exemplares de $N$. albiventris abandonavam o local, partindo quase todos em direção ao rio São Francisco. Um pequeno grupo, entretanto, foi observado voando diretamente para uma fresta do outro lado da ponte e lá permanecendo até o amanhecer, tratando-se de parte de uma das colônias que usavam o local como refúgio diurno.

A atividade noturna aqui descrita para $R$. naso e $N$. albiventris pode ser evidenciada através da Fig. 2, na qual aparece o número estimado de indivíduos, em ambas as espécies, que compartilhavam o abrigo estudado ao longo do período de observação.

\section{Estratégia reprodutiva}

Dentre os 41 exemplares de $R$. naso capturados foi possível identificar 2 fêmeas grávidas em outubro/94, 1 lactante em abril/94, 5 em outubro/94 e 3 em maio/95. Nos 41 exemplares de $N$. 
albiventris examinados, constataram-se 3 fêmeas lactantes em abril/94 e 2 em outubro/94. Durante observações sobre o padrão de atividade realizadas em outubro/94, verificou-se a presença de filhotes em ambas as espécies. Notou-se ainda, em relação a $R$. naso, a ocorrência concomitante em uma mesma colônia de uma fêmea grávida e filhotes em diferentes estágios de desenvolvimento.

\section{Relações intra e interespecíficas}

Colônias de $R$. naso com 10 a 30 indivíduos apresentavam um padrão oval no arranjo espacial de seus integrantes, com intervalo de 1 a $15 \mathrm{~cm}$ entre eles. Na maior colônia (aprox. 80 indivíduos), entretanto, foi possível encontrar formações ovais e lineares, e ainda indivíduos destacados a diferentes distâncias desses agrupamentos sem um aparente padrão (Fig. 1).

No período reprodutivo, fêmeas dessa espécie e seus filhotes ficavam no mesmo abrigo, mas isolados da colônia principal. Durante o forrageio dos adultos, os filhotes permaneciam no abrigo, onde ensaiavam vôos de aprendizado. Ao retornar, a fêmea pousava ao lado do filhote e, tocando-lhe com o antebraço, parecia dar-lhe um sinal para que ele se juntasse a ela, o que acontecia logo em seguida. Para facilitar o acesso do filhote ao seu ventre, a fêmea erguia a parte anterior de seu corpo, aumentando o espaço entre ela e a superfície do abrigo.

A colônia maternidade, composta por cerca de 9 indivíduos, situava-se mais ao centro da ponte, posicionada diretamente sobre a água, em área mais exposta que a da colônia principal.

Com relação a $N$. albiventris, constatou-se que diferentes colônias ocupavam um mesmo local como refúgio noturno. O contato corpóreo entre indivíduos de diferentes colônias foi confirmado por integrantes de uma colônia que se abrigavam na mesma ponte durante o dia e que foram vistos abandonando um grande agrupamento e se dirigindo ao local de repouso diurno.

Apesar da considerável proximidade entre os locais de repouso de $R$. naso e $N$. albiventris na ponte onde ambas as espécies coabitavam, nenhuma interação agressiva foi notada. Observou-se, inclusive, um exemplar de $N$. albiventris pousar acidentalmente sobre um filhote de $R$. naso, tendo-se afastado imediatamente sem problemas aparentes para ambos.

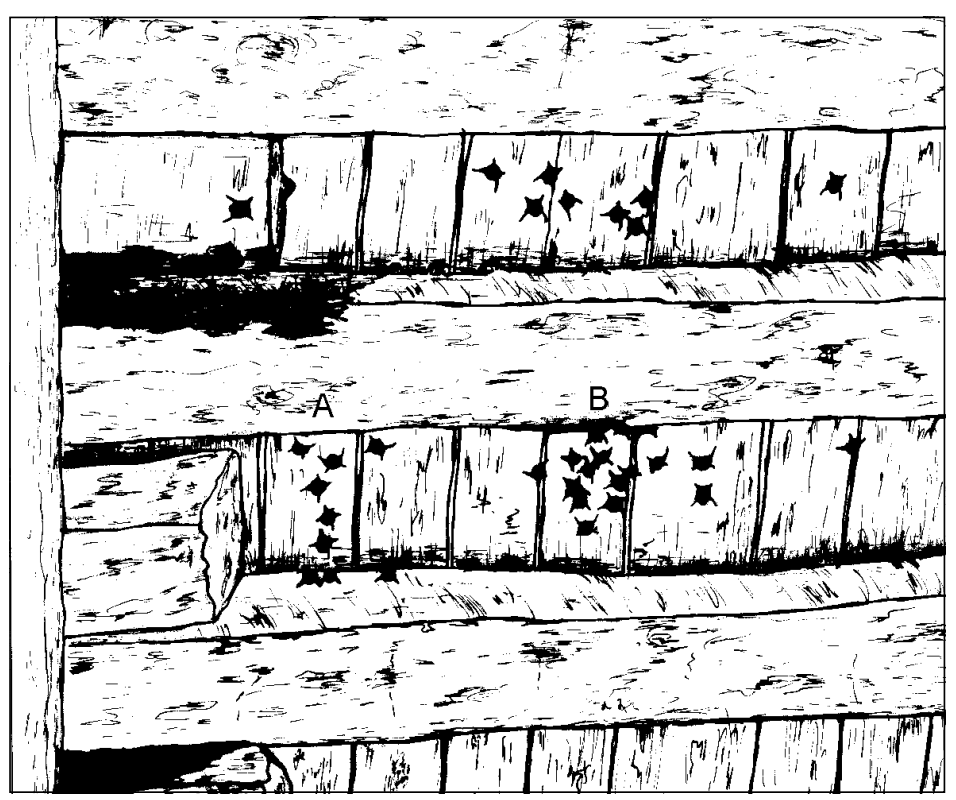

Fig. 1 - Disposição dos indivíduos de uma colônia de R. naso que se abrigava sob ponte de madeira no riacho Mocambinho, região de Jaíba. Note a ocorrência de formações lineares (A) e ovais (B). Frestas entre as vigas, com manchas escuras resultantes do acúmulo de urina, eram ocupadas por colônias de N. albiventris. (Barra: $12 \mathrm{~cm}$.) 


\section{DISCUSSÃO}

\section{Localização e tamanho das colônias}

A presença de $R$. naso e $N$. albiventris em áreas sob considerável ação antrópica demonstra certo grau de plasticidade dessas espécies diante das alterações ambientais. Abrigos artificiais podem ser mais propícios do que os naturais, como notou-se em relação a $R$. naso, que, apesar da disponibilidade de recursos providos por uma mata ciliar, utilizava uma ponte como refúgio primário. Essa mesma ponte abrigava cerca de 80 indivíduos, número elevado considerando-se que colônias dessa espécie na Costa Rica variavam entre 3 e 45 indivíduos (Bradbury \& Vehrencamp, 1976) e no México, em sua maioria, entre 10 e 25 (Dalquest, 1957). Como constatado por Marques (1985) em relação ao frugívoro Carollia perspicillata (Phyllostomidae) em bueiros, o tamanho do abrigo pode ser o fator determinante, já que em duas pontes menores colônias de $R$. naso restringiram-se a cerca de 30 indivíduos.

Como a maioria das espécies que ocupam construções humanas e cavernas como refúgio (Lewis, 1995), R. naso e N. albiventris mostraramse fiéis a seus abrigos, permanecendo neles durante todo o período de estudo. Uma exceção notada foi a colônia de $R$. naso que abandonou o refúgio durante a estação seca. Tal fato indica que, em relação à localização dos abrigos, esta espécie é diretamente dependente de coleções d'água, como já anteriormente sugerido (Plumpton \& Jones, 1992).

\section{2. Áreas de forrageio}

A variedade de hábitats em que $N$. albiventris foi observada forrageando demonstra o maior oportunismo dessa espécie em relação a $R$. naso, exclusivamente amostrada sobre cursos d'água. Deve-se considerar, entretanto, que todas as localidades em que $N$. albiventris forrageava sobre o solo encontravam-se nas proximidades de rios, o que deixa clara a associação dessa espécie com cursos d'água, onde mais freqüentemente foi observada se alimentando. Esses dados corroboram as citações de Dalquest (1957) e Bradbury \& Vehrencamp (1976) em relação a $R$. naso e de Hood \& Pitocchelli (1983) sobre $N$. albiventris.

Apesar de ambas as espécies aparentemente forragearem no mesmo nível de estratificação vertical, a possibilidade de $N$. albiventris utilizar inse- tos aquáticos como recurso alimentar (Whitaker \& Findley, 1980), não evidenciada em $R$. naso (Dalquest, 1957), atuaria reduzindo a competição interespecífica. Suthers \& Fattu (1973) constataram em cativeiro que $N$. albiventris apresenta um comportamento de caça similar ao de $N$. leporinus, utilizando chamados de ecolocação para detectar presas disponíveis na superfície da água, capturando-as com as patas traseiras. Tal hábito, também observado por Brown et al. (1983) sob condições naturais, poderia explicar os freqüentes contatos aqui mencionados de indivíduos dessa espécie na superfície da água.

\section{Padrão de atividade}

Os dados obtidos sobre $R$. naso apontam um padrão bimodal de atividade com forrageios ao final do crepúsculo e antes da alvorada. N. albiventris apresenta um primeiro período de atividade bem definido e que se sobrepõe ao de $R$. naso, como demonstrado na Fig. 2, em que ambas as espécies se mostram ausentes do abrigo ao final do crepúsculo. O segundo, entretanto, não foi comum a todos indivíduos, o que deve refletir as observações de Fenton et al. (1993), que através de radiotelemetria constataram uma variação individual e de noite para noite na atividade dessa espécie, não sendo possível enquadrá-la em um padrão generalizado. Contudo, os resultados aqui obtidos permitem concluir que $N$. albiventris apresenta de um a dois períodos de atividade e que ambos se sobrepõem aos de $R$. naso. Um padrão bimodal de atividade tem sido referido não só para $N$. albiventris (Brown, 1968; Hooper \& Brown, 1968; Brown et al., 1983), como para outros morcegos insetívoros (Anthony \& Kunz, 1977; Marques, 1986; Chase et al., 1991) e pode refletir uma maior abundância na disponibilidade de insetos, como sugerido por Marques (1986).

O retorno parcial dos integrantes das colônias de $R$. naso indica que, como observado por Dalquest (1957), esta espécie utiliza abrigos secundários durante a noite. A constatação de que as fêmeas que deixam seus filhotes no abrigo diurno retornam a este logo após o forrageio pode indicar que estas apresentam uma menor área de alimentação que a dos demais integrantes da colônia, como observado por Bradbury \& Vehrencamp (1976). A utilização de abrigo secundário por $N$. albiventris foi comprovada diretamente, e suas possíveis funções são abordadas mais adiante. 


\section{Estratégia reprodutiva}

Os resultados obtidos sugerem que, na área de estudo, $R$. naso e $N$. albiventris apresentam um padrão poliestro bimodal, com nascimentos ocorrendo no início e no final do período chuvoso. A sazonalidade reprodutiva notada em $R$. naso foi constatada também por Bradbury \& Vehrencamp (1976) na Costa Rica, onde filhotes não foram observados durante a estação seca. Em certas partes de sua distribuição, entretanto, essa espécie pode se reproduzir ao longo de todo o ano (Plumpton \& Jones, 1992). Segundo Taddei (1980), variação geográfica também ocorre no padrão reprodutivo de $N$. albiventris, e enquanto na região amazônica a poliestria bimodal foi sugerida por Marques (1985), na América Central essa espécie tem sido referida como monoestra (Anderson \& Wimsatt, 1963; Hooper \& Brown, 1968). O caráter assincrônico dos partos, característico em $R$. naso (Bradbury \& Vehrencamp, 1976), também foi registrado no presente estudo através da constatação simultânea de uma fêmea grávida e filhotes em diferentes estágios de desenvolvimento.

\section{Relações intra e interespecíficas}

$O$ padrão oval de arranjo espacial entre os integrantes das colônias de $R$. naso foi predominante no tipo de abrigo estudado (pontes), o que possivelmente se deve ao maior espaço disponível nestes do que em troncos de árvores, onde a formação linear é mais freqüentemente utilizada. A observação de formações lineares e ovais simultaneamente na colônia mais numerosa pode refletir a existência de subgrupos em sua composição.

A separação das fêmeas de $R$. naso durante o período reprodutivo mencionada por Dalquest (1957) e Bradbury \& Vehrencamp (1976) foi verificada, constatando-se entretanto que, ao contrário do observado por Dalquest (1957), as fêmeas podem permanecer com seus filhotes no mesmo abrigo utilizando local distinto, que pode ser ainda mais exposto que o da colônia principal. Uma ponte mais alta favorece os ensaios de vôo dos filhotes, mas não elimina o risco de uma possível queda na água. Um filhote de $N$. albiventris com o corpo ainda desprovido de pêlos e antebraço medindo 27,40 $\mathrm{mm}$ foi encontrado agonizando na margem do riacho sob a ponte, completamente envolvido por formigas "lava-pés" (Solenopsis sp.), custo que parece ser relevado em função das vantagens apresentadas por este abrigo.
A utilização de refúgio noturno por N. albiventris pode, em primeira instância, ser associada à digestão do alimento, já que indivíduos capturados logo após o forrageio apresentavam seus abdômens dilatados, demonstrando ampla capacidade de ingestão e considerável aumento no peso. Contudo, levando-se em conta o tamanho da ponte utilizada como abrigo e a quantidade de frestas disponíveis em outras partes dessa ponte, questiona-se por que um número tão elevado (cerca de 200) de morcegos provenientes de distintas colônias se agrupariam todos no mesmo local, ampliando ainda mais os potenciais custos relativos à predação (Fenton et al., 1994). A termorregulação pode ser a resposta. Roverud \& Chappell (1991) concluíram que, quando $N$. albiventris abriga-se em agrupamentos, diminui consideravelmente seus gastos energéticos, reduzindo as taxas de perda de calor. Estes autores inferiram ainda que tal hábito reduz o risco de predação, já que o tempo necessário para esta espécie atingir a temperatura basal mínima de vôo é consideravelmente menor em agrupamentos que em morcegos solitários.

Analisando-se os diversos parâmetros que têm influência na presença de $R$. naso e $N$. albiventris em simpatria, conclui-se que, apesar de apresentarem períodos de atividade e reprodução similares, o maior oportunismo de $N$. albiventris em relação às áreas de forrageio e sua capacidade de explorar insetos aquáticos como recurso alimentar por certo contribuem para evitar a sobreposição de nichos. Sabe-se ainda que $R$. naso preda insetos de tamanho reduzido (Dalquest, 1957), aos quais $N$. albiventris provavelmente não deve se restringir em função de seu maior porte. Uma evidência dessa forma de compartilhar os recursos pode ser obtida comparando-se os resultados de análises de conteúdo estomacal já descritas para essas espécies. Enquanto insetos predados por indivíduos de R. naso, estudados por Bradbury \& Verhencamp (1976) em Guanacaste, Costa Rica, apresentaram comprimento médio estimado em $2,42 \mathrm{~mm}$, os utilizados por $N$. albiventris, provenientes da mesma província, variaram entre 4 e 20 mm (Hooper \& Brown, 1968).

Em função de seus diferentes hábitos de postura durante o repouso e adaptação à luminosidade, $R$. naso e N. albiventris ocupam de maneira distinta um mesmo abrigo (ponte), podendo coabitar sem competição direta por espaço. A relação entre $R$. naso e $N$. albiventris, que de acor- 
do com as considerações de Graham (1988) estariam ocupando o mesmo sítio no refúgio $(<0,5 \mathrm{~m}$ entre os indivíduos), mostrou-se harmônica e possivelmente neutra (Graham, 1988). Contudo, apesar dos locais de repouso serem distintos, N. albiventris, ao pousar na ponte, não o faz diretamente nas frestas. Se todos os indivíduos dessa espécie e de $R$. naso que, de alguma forma, utilizavam a ponte sobre o riacho Mocambinho a ocupassem ao mesmo tempo, a probabilidade de acidentes relacionados à sobreposição dos locais de pouso e, conseqüentemente, a energia gasta para localizar pontos livres seriam maiores. Tal fator, que elevaria os custos nessa interação, podendo torná-la negativa (Graham, 1988), é, entretanto, consideravelmente reduzido pelas diferentes estratégias empregadas por essas espécies no uso do abrigo. Como se pode notar na Fig. 2, a partilha temporal observada na ocupação da ponte, utilizada primariamente como refúgio diurno por $R$. naso e noturno por $N$. albiventris, demonstra mais uma vez a compatibilidade de sua coexistência em uma dada área.

Agradecimentos - Agradecemos aos Profs. Adriano Lúcio Peracchi e Gonzalo E. Moya Borja pela leitura crítica e sugestões ao manuscrito; aos funcionários da Estação Agroclimática de Mocambinho - 83389, EPAMIG/FEMO, pelos dados gentilmente fornecidos; a Tereza R. Nogueira pela elaboração da ilustração dos morcegos no abrigo; e a SYTEC 3 Engenharia e Controle de Corrosão LTDA., que na qualidade de gestora dos Serviços de Monitoramento, Deslocamento e Salvamento da Fauna do Projeto Jaíba, mantidos pela CODEVASF, possibilitou a realização deste trabalho.

\section{REFERENCIAS BIBLIOGRÁFICAS}

ANDERSON, J. W. \& WIMSATT, W. A., 1963, Placentation and fetal membranes of the Central American noctilionid bat, Noctilio labialis minor. Amer. J. Anat., 112: 181-202.

ANDRADE-LIMA, D., 1981, The caatingas dominium. Rev. Brasil. Bot., 4(2): 149-163.

ANTHONY, E. L. P. \& KUNZ, T. H., 1977, Feeding strategies of the little brown bat, Myotis lucifugus, in southern New Hampshire. Ecology, 58: 775-786.

BRADBURY, J. W. \& VEHRENCAMP, S. L., 1976, Social organization and foraging in emballonurid bats. I. Field studies. Behav. Ecol. Sociobiol., 1: 337-381.

BROOKE, A. P., 1994, Diet of the fishing bat, Noctilio leporinus (Chiroptera: Noctilionidae). J. Mamm., 75(1): 212-218.

BROWN, J. H., 1968, Activity patterns of some Neotropical bats. J. Mamm., 49: 754-757.

BROWN, P. E., BROWN, W. T. \& GRINNELL, A. D., 1983, Echolocation, development, and vocal communication in the lesser bulldog bat, Noctilio albiventris. Behav. Ecol. Sociobiol., 13: 287-298.

CHASE, J., SMALL, M. Y., WEISS, E. A., SHARMA, D. \& SHARMA, S., 1991, Crepuscular activity of Molossus molossus. J. Mamm., 72(2): 414-418.

DALQUEST, W. W., 1957, Observations on the sharp-nosed bat, Rhynchiscus naso (Maximilian). Texas J. Sci., 9: 219-226.

EITEN, G., 1972, The cerrado vegetation of Brasil. Bot. Rev., 38: 201-341.

FENTON, M. B., AUDET, D., DUNNING, D. C., LONG, J., MERRIMAN, C. B., PEARL, D., SYME, D. M., ADKINS, B., PEDERSEN, S. \& WOHLGENANT, T., 1993, Activity patterns and roost selection by Noctilio albiventris (Chiroptera: Noctilionidae) in Costa Rica. $J$. Mamm., 74(3): 607-613.

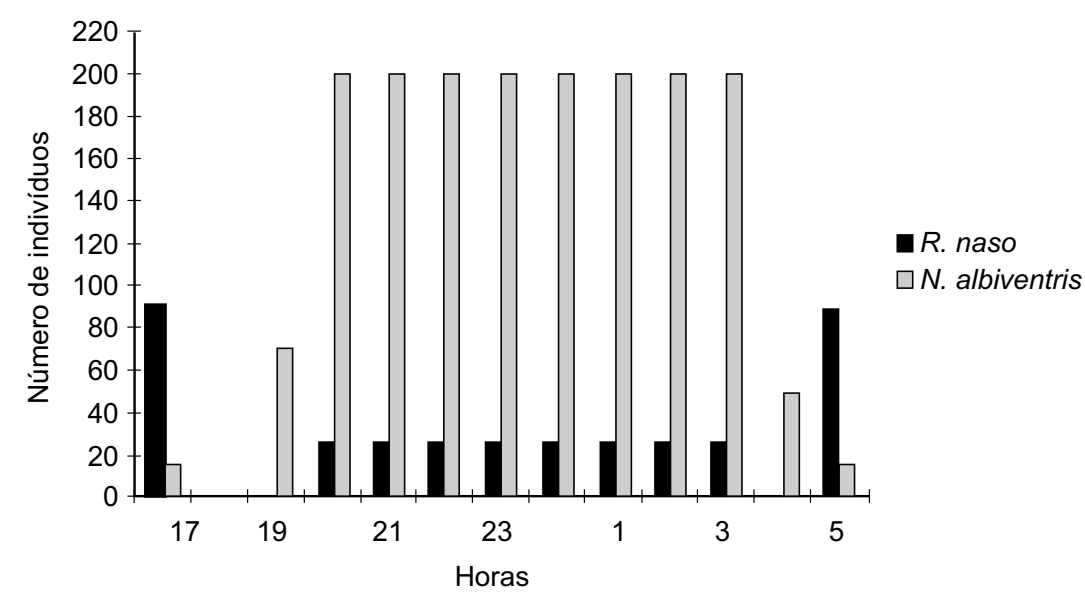

Fig. 2 - Número estimado de indivíduos de R. naso e de N. albiventris que partilhavam abrigo sob ponte no riacho Mocambinho, região de Jaíba. Morcegos registrados às 17 e às 5 horas constituíam as colônias que ocupavam o local como abrigo diurno. 
FENTON, M. B., RAUTENBACH, I. L., SMITH, S. E., SWANEPOEL, C. M., GROSELL, J. \& JAARSVELD, J. van, 1994, Raptors and bats: threats and opportunities. Anim. Behav., 48: 9-18.

FERNANDES, A. \& BEZERRA, P., 1990, Estudo Fitogeográfico do Brasil. Stylus Comunicações, Fortaleza, 205p.

GOODWIN, G. G. \& GREENHALL, A. M., 1961, A review of the bats of Trinidad and Tobago. Bull. Amer. Mus. Nat. Hist., 122: 187-302.

GRAHAM, G. L., 1988, Interespecific associations among peruvian bats at diurnal roosts and roost sites. J. Mamm., 69: 711-720.

HOOD, C. S. \& PITOCCHELLI, J., 1983, Noctilio albiventris. Mammalian Species, 197: 1-5.

HOOPER, E. T. \& BROWN, J. H., 1968, Foraging and breeding in two sympatric species of neotropical bats, genus Noctilio. J. Mamm., 49: 310-312.

HOWELL, D. J. \& BURCH, D., 1974, Food habits of some Costa Rican bats. Rev. Biol. Trop., 21: 281-294.

LEWIS, S. E., 1995, Roost fidelity of bats: a review. $J$. Mamm., 76(2): 481-496.

McNAB, B. K., 1971, The structure of tropical bat faunas. Ecology, 52(2): 352-358.

MAGALHÃES, G. M. \& FERREIRA, M. B., 1976, Vegetação, pp. 81-137. In: Levantamento de reconhecimento com detalhes dos solos do Distrito Agroindustrial de Jaíba - Minas Gerais. Bol. Téc. EMBRAPA EPAMIG/RURAL MINAS, 54, 242p.

MARQUES, S. A., 1985, Novos registros de morcegos do Parque Nacional da Amazônia (Tapajós), com observações do período de atividade noturna e reprodução. Bol. Mus. Par. Emilio Goeldi, zool., 2(1): 71-83.

MARQUES, S. A., 1985, Espécies associadas e algumas características físicas influindo na presença de Carollia perspicillata em bueiros na região de Manaus, AM (Mammalia, Chiroptera: Phyllostomidae). Acta Amazon., 15(1-2): 243-248.

MARQUES, S. A., 1986, Activity cycle, feeding and reproduction of Molossus ater (Chiroptera: Molossidae) in Brasil. Bol. Mus. Par. Emilio Goeldi, zool., 2(2): 159-179.

NOWAK, R. M., 1994, Walker's Bats of the world. John Hopkins University Press, Baltimore e London, 287p.

PLUMPTON, D. L. \& JONES, J. K., Jr., 1992, Rhynchonycteris naso. Mammalian Species, 413: 1-5.

REIS, N. R., 1984, Estrutura de comunidade de morcegos na região de Manaus. Rev. Brasil. Biol., 44(3): 247-254.

ROVERUD, R. C. \& CHAPPELL, M. A., 1991, Energetic and thermoregulatory aspects of clustering behavior in the neotropical bat Noctilio albiventris. Physiol. Zool., 64: 1527-1541.

SUTHERS, R. A. \& FATTU, J. M., 1973, Fishing behaviour and acoustic orientation by the bat (Noctilio labialis). Anim. Behav., 21: 61-66.

TADDEI, V. A., 1980, Biologia reprodutiva de Chiroptera: perspectivas e problemas. Interfacies, São José do Rio Preto, 6: 1-18.

TUTTLE, M. D., 1970, Distribution and zoogeography of Peruvian bats, with comments on natural history. Univ. Kans. Sci. Bull., 49: 45-86.

VELOSO, H. P., RANGEL, A. L. R. \& LIMA, J. C. A., 1991, Classificação da vegetação brasileira adaptada a um sistema universal. IBGE, Departamento de Recursos Naturais e Estudos Ambientais, Rio de Janeiro, 124p.

WHITAKER, J. O., Jr. \& FINDLEY, J. S., 1980, Foods eaten by some bats from Costa Rica and Panama. J. Mamm., 61(3): 540-544. 